\title{
Isolation of Aspergillus ochraceus and Production of Ochratoxin in Coffee Samples
}

\author{
Pratikshya Pandit ${ }^{1}$, Om Prakash Panta ${ }^{1}$ and Tika Bahadur Karki ${ }^{2}$ \\ ${ }^{\prime}$ National College, Kathmandu Nepal \\ ${ }^{2}$ Department of Biotechnology, Kathmandu University, Dhulikhel, Nepal \\ e-mail:pratu35@yahoo.com
}

\begin{abstract}
The occurrence of mycotoxins in foods and feeds has long been recognized as a potential hazard for human and animal health due to their severe toxic and carcinogenic properties. Among various mycotoxins, ochratoxin A (OTA) is the most hazardous one because of its serval contamination cases in the world. In this study contamination levels of Aspergillus ochraceus in coffee samples were assessed, where two strains of it were isolated from 65 coffee samples. They were confirmed by using Czapeck yeast extract agar (CYA). Fermentation was carried out for ochratoxin production at different moisture levels: $20 \%, 40 \%$ and $60 \%$ by using coffee as a substrate. The extract was assayed for the presence of ochratoxin by thin layer chromatography (TLC). Results showed that high production of this toxin (402 ppb) was obtained in coffee containing 60\% of moisture after 19 days of incubation period with high load of fungal growth and the effect of roasting on coffee containing ochratoxin was observed where the level of it was decreased after roasting. It can be concluded that coffee substrate with high level of moisture favored good condition for the growth of A. ochraceus and ochratoxin formation.
\end{abstract}

Key words: coffee, Aspergillus ochraceus, OTA, CYA, TLC

\section{Intoduction}

Ochratoxins are a group of mycotoxins produced by some Aspergillus species (mainly A. ochraceus but also by A. niger) and some Penicillium species, especially P. verrucosum (Pitt 1987). Ochratoxin A is the most prevalent and relevant fungal toxin of this group, while ochratoxins $\mathrm{B}$ and $\mathrm{C}$ are of lesser importance. The toxic effect of mycotoxins on animal and human health is referred to as mycotoxicosis, the severity of which depends on the toxicity of the mycotoxin, the extent of exposure, age and nutritional status of the individual and possible synergistic effects of other chemicals to which the individual is exposed (Peraica et al. 1999). According to Smith and Moss (1985) the most commonly acute effects of mycotoxin poisoning leads to deterioration of the liver and kidney functions, allergic response and immune suppression, which in extreme cases leads to death, whereas chronic effects include mutagenicity, teratogenicity and carcinogenicity (Mello \& Macdonald 1997, Pitt 2000).
Ochratoxin A (OTA) structurally consists of a para-chlorophenolic group containing a dihydroisocoumarin moiety that is amide-linked to L-phenyl alanine (Khoury et al. 2010). It has been shown to exibit nephrotoxic, immune suppressive, teratogenic and carcinogenic properties (Hohler 1998).

The International Agency for Research on Cancer (IARC) has classified OTA as a possible human carcinogen (group 2B), based on sufficient evidence for carcinogenicity in experimental animal studies and inadequate evidence in humans (IARC 1993). OTA frequently occurs as a contaminant in cereals worldwide and is also reported in coffee (Le-Bars \& Le Bars 2000). A. ochraceus is thought to be the most important OTA producing mould in relation to coffee beans (Pitt 2000).

Coffee is relatively new crop in Nepal. It was introduced in Gulmi district of Lumbini zone at around 1937 AD. Nepal has potential for producing organic 
coffee due to the availability of soil with fragile nature and appropriate climate in the mid hill (Nepal 2006). In Nepal, studies on ochratoxin have not been carried out, where coffee beans are dried, the green beans contain $55 \%$ total polysaccharides, 8 to $15 \%$ fat depending on the variety, and around $11 \%$ protein, plus 10 to $13 \%$ water, alkaloids (including caffeine), and minerals (potassium, calcium, magnesium and phosphorus) which favors the growth of different types of fungus in presence of high amount of moisture. Fungi are significant environmental microorganisms especially in foods where they are responsible for spoilage, production of mycotoxins and, in some cases desirable bioconversions. Among them, ochratoxin A is nephrotoxic and carcinogenic to some animals and has been detected in different types of foods such as cocoa and cocoa products, coffee, dried fruits, cereals wines, beer and others. A. ochraceus has been isolated from several green coffee samples originating from coffee producing countries. It is important to detect the contamination of coffee by ochratoxin producing fungi in Nepal.

\section{Methodology}

\section{Isolation and identification of $A$. ochraceus}

Fungi associated with green and roasted ground coffee beans samples were isolated according to the procedure given by International groundnut Aspergillus flavus Nursery (IGAFN 1980).

For the isolation of mold associated with coffee samples, coffee beans were surfacely disinfected with $70 \%$ ethanol for 2 minutes and sodium hypochlorite for 3 minutes, washed with distilled water and dried in two layers of sterile filter papers. Subsequently, the beans were aseptically plated on potato dextrose agar (PDA) in order to isolate the associated internal micro flora. For powder samples, $10 \mathrm{~g}$ of coffee was taken and serial dilutions were performed and spread plate were done on PDA medium. The plates were incubated for 7 to 14 days at $28^{\circ} \mathrm{C}$. After incubation, Aspergillus like colonies were sub-cultured on Czapek yeast extract agar (CYA) plates and thus obtained fungal colonies particularly A. ochraceus group were isolated and maintained on CYA. Identification was done on the basis of cultural and morphological characteristics described by Lactophenol Cotton Blue Staining Method (Aneja 2008, Pitt \& Hocking 1997). The stock cultures of isolated colonies were maintained on CYA and PDA slants and preserved at $4{ }^{\circ} \mathrm{C}$.

\section{Growth curve of Aspergillus ochraceus}

Pure cultures of isolated strains of A. ochraceus were point inoculated on CYA plates separately and incubated at $28^{\circ} \mathrm{C}$ and growth of the cultures were measured. Taking measurement of diameter each day the growth curve of fungal isolates were drawn and their linear and maximum growth were determined (Aneja 2008).

\section{Fungal culture and ochratoxin production} Fermentation was carried out in $500 \mathrm{ml}$ Erlenmeyer flask containing $25 \mathrm{~g}$ of Coffee. Initial moisture content of the substrate was determined by hot air oven method (KC \& Rai 2007). Each substrate was inoculated with different strains of A. ochraceus by adjusting $20 \%$, $40 \%$ and $60 \%$ moisture content with addition of water and incubated at $28^{\circ} \mathrm{C}$ for 20 days. During this time interval the level of ochratoxin and number of colony of mold was determined at different interval of time (Lindenfelser 1975, Bacon et al. 1973).

\section{Extraction of ochratoxin}

Extraction of ochratoxin from the solid substrate was carried out according to the Official Methods of Analysis (AOAC 1990) at every five days. The toxin was extracted by adding $12.5 \mathrm{ml}$ of water and $125 \mathrm{ml}$ of chloroform and allowed to shake for $30 \mathrm{~min}$ on mechanical shaker. The mixture was filtered through Whatmann No.1 filter paper and the filtrate was again filtered through anhydrous sodium sulfate and chloroform was evaporated till dryness and toxins were identified on thin layer chromatography (TLC).

\section{Quantification and Estimation of ochratoxin content}

Quantification of ochratoxin was done by TLC using comparison of standards by visual technique. During loading about $500 \mu \mathrm{l}$ of acetic acid: benzene (1:99) was added to the extract residue and $5 \mu$ of sample extract was spotted on the TLC plate. Similarly, $5 \mu$ of standard ochratoxin having concentration 5ppm, 10ppm, 15ppm, 20ppm were spotted on the same TLC plate. The plate was then dipped into chromatographic tank containing solvent benzene: methanol: acetic acid (8:1:1) until the solvent moved up to the top of the plate (ie.up to 10$12 \mathrm{~cm}$ ) from the point of initial load. The TLC plate was dried and viewed in UV chamber at $365 \mathrm{~nm}$ wavelength. Ochratoxin was observed as greenish blue color. The color intensity of the sample was matched with the color intensity of the standard solution. Then the concentration of ochratoxin was calculated (Helrich 1990). 


\section{Confirmation of the ochratoxin}

The identity of the ochratoxin in the extract was confirmed by the presumptive test with alcoholic $\mathrm{NaHCO}_{3}$. In this test alcoholic $\mathrm{NaHCO}_{3}$ was sprayed on TLC plate, dried and observed under long wave length. Where fluorescence was changed from greenish blue to blue and increased in intensity (Helrich 1990).

\section{Effect of heat on ochratoxin}

Coffee samples that contained ochratoxin were taken and $25 \mathrm{~g}$ of it was kept at hot air oven for roasting, the time was varied from 12 to $20 \mathrm{~min}$, and the roasted colour varied from light medium to dark. The differences in OTA reduction between different levels of roasting was determined to see the effect of heat on the toxin (Vander Stegen et al. 2001).

\section{Results and Discussion}

Of 65 coffee samples, two samples showed the presence of $A$. ochraceus. These samples also contained different types of fungi. All together 53 samples of coffee beans were contaminated with different types of fungi such as A. flavus, A. niger, Mucor spp. Rhizopus spp. Penicillium spp. Fusarium spp.

A. ochraceus spp. isolated from coffee beans which were collected from Argakhachi and Kathmandu valley. Mostly fungi were isolated from coffee beans; among Table 1. Morphology of isolated strain

\begin{tabular}{l|l}
\hline Colony morphology & Descriptions \\
\hline Colony color in CYA & $\begin{array}{l}\text { Yellow brown in young } \\
\text { and darkening with age } \\
\text { with a dark brown, reverse } \\
\text { in yellow to amber yellow. } \\
\text { Spherical to subspherical }\end{array}$ \\
Vesicle & and densely packed \\
& metulae \\
Yellow-Brown, rough \\
Hyphae & Trailing \\
Metulaes & Densely packed \\
Arrangement of conidia & Irregular, nearly smooth \\
Phialides & Biseriate, with small \\
& smooth, pale brown \\
& conidia \\
\hline
\end{tabular}

12 samples of coffee powder only three samples were contaminated with fungi.

All the macroscopic characteristics of the isolates were similar to that of the A. ochraceus indicating that the isolates are most likely the strains of A. ochraceus.
A. ochraeceus with other fungi was identified by recognizing characteristics structure seen in cultures. The identification of fungi was based on cultural characteristics and morphological characters. The cultural characters observed were surface texture, color and the reverse side of mould on agar plate and microscopic characters were type of mycelium, type of spore, pigmentation. etc.

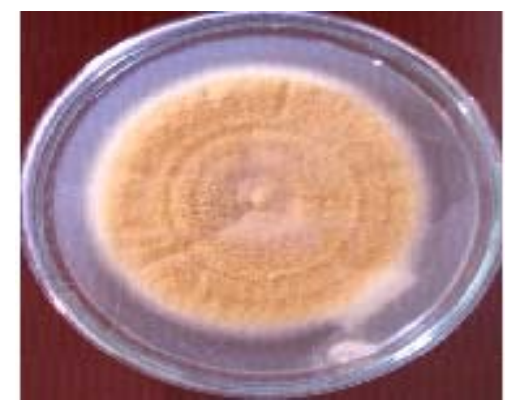

Photo 1. Colony surface of A. ochraceus on CYA media

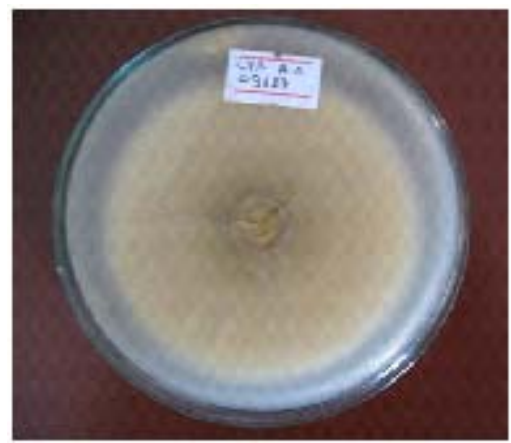

Photo 2. Colony reverse of A. ochraceus on CY A media

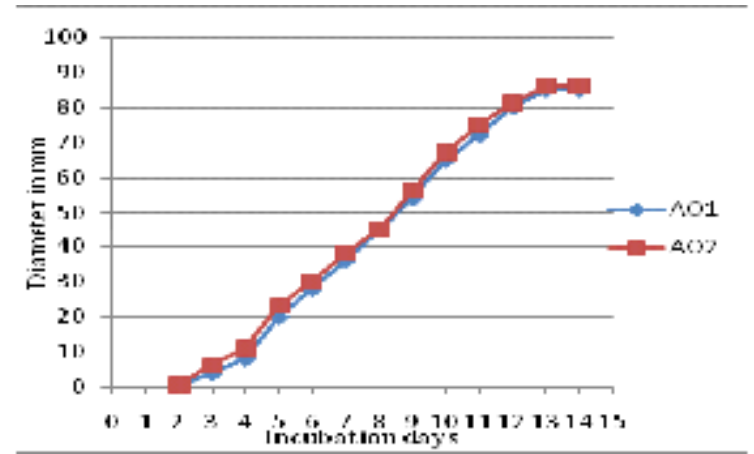

Fig. 1. Linear growth of fungal isolates $\mathrm{AO}_{1}$ and $\mathrm{AO}_{2}$. The figure shows that $\mathrm{AO}_{2}$ is the fast growing fungus than $\mathrm{AO}_{1} \cdot \mathrm{AO}_{2}$ reached its maximum size of $86 \mathrm{~mm}$ on the $13^{\text {th }}$ day while $\mathrm{AO}_{1} 85 \mathrm{~mm}$ on the $13^{\text {th }}$ day 
Enumeration of $A$. ochraceus $\left(\mathrm{AO}_{1}\right.$ and $\left.\mathrm{AO}_{2}\right)$ and detection of ochratoxin during fermentation

During the fermentation of the coffee sample at different moisture content, growth of fungi and the level of toxins were determined at the interval of 5 days. For the enumeration of fungi, one gram of sample was taken from each of the fermenting flask and dilution was performed up to $10^{-6}$. Ochratoxin was detected by taking $25 \mathrm{~g}$ of sample according to AOAC protocol.

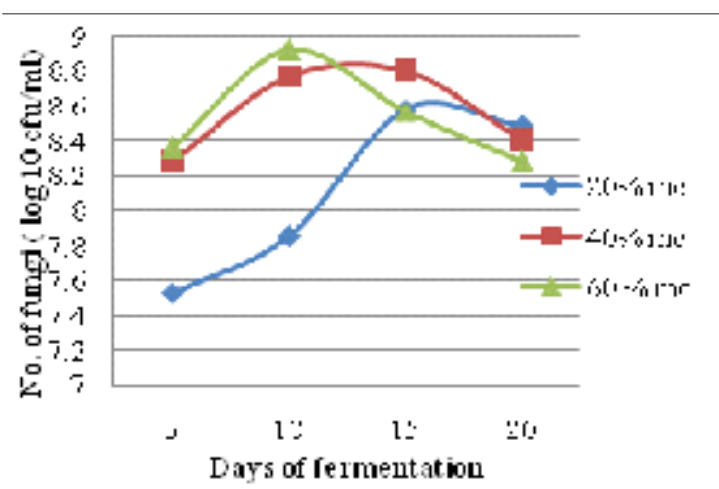

Fig. 2. Growth of A. ochraceus $\left(\mathrm{AO}_{1}\right)$ during fermentation

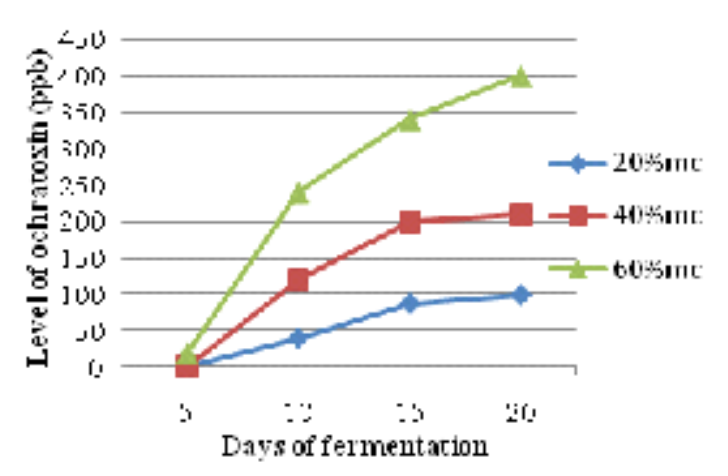

Fig. 3. Level of ochratoxin produced by A. ochraceus $\left(\mathrm{AO}_{1}\right)$ during fermentation

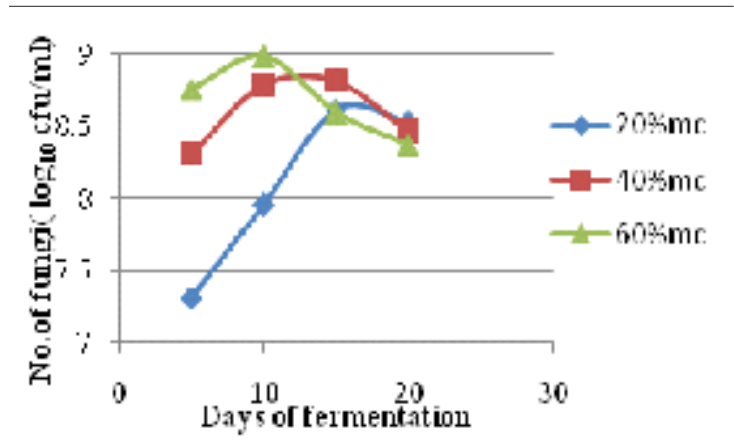

Fig. 4. Growth of A. ochraceus $\left(\mathrm{AO}_{2}\right)$ during fermentation

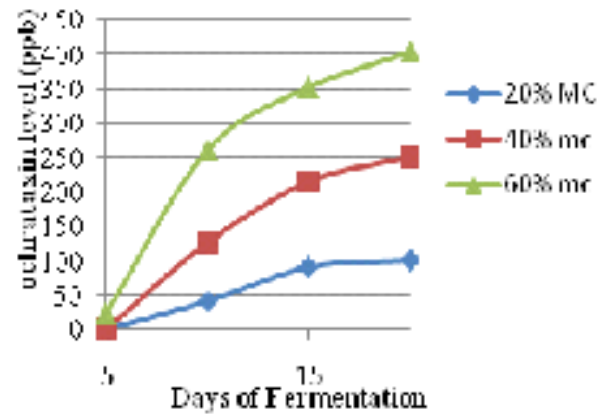

Fig. 5. Level of ochratoxin produced by A. ochraceus $\left(\mathrm{AO}_{2}\right)$ during fermentation

The moisture content showed a marked influence on growth of A. ochraceus and ochratoxin A production. High numbers of $A$. ochraceus were present at $60 \%$ moisture after 5 days of incubation, in case of both strains, where the number of strain $\mathrm{AO}_{1}$ was found to be $\log 8.6$ and $\mathrm{AO}_{2}$ was found to be $\log 8.76$. No more variation was found in growth of A. ochraceus in $40 \%$ and $60 \%$ moisture content. After 15 days of incubation the growth of A.ochraceus was at low level at $20 \%$ moisture in comparisons to $40 \%$ and $60 \%$. The load of organisms was slightly in decline phase after 20 days of incubation. Similarly, detectable amount of ochratoxin A was produced after 4 days of incubation at $60 \%$ moisture, whereas ochratoxin $\mathrm{A}$ was detected after 9 days of incubation in $20 \%$ and $40 \%$ moisture content. Maximum level of toxin was produced at $60 \%$ moisture content after 19 days of incubation.

The high level of toxin produced by $\mathrm{AO}_{1}$ strain was $400 \mathrm{ppb}$ in $60 \%$ moisture followed by $215 \mathrm{ppb}$ and $100 \mathrm{ppb}$ in $40 \%$ and $20 \%$ respectively, whereas maximum ochratoxin produced by $\mathrm{AO}_{2}$ strain was $402 \mathrm{ppb}$ at $60 \%$ moisture followed by $210 \mathrm{ppb}$ and $100 \mathrm{ppb}$ in $40 \%$ and $20 \%$ moisture respectively.

\section{Effect of roasting on ochratoxin A level in coffee beans}

Coffee sample which consisted ochratoxin was roasted for different interval of time and the content of toxin was determined according to AOAC. The effect of roasting was observed by determining the amount of ochratoxin. The result obtained is depicted below in Fig 6 . 


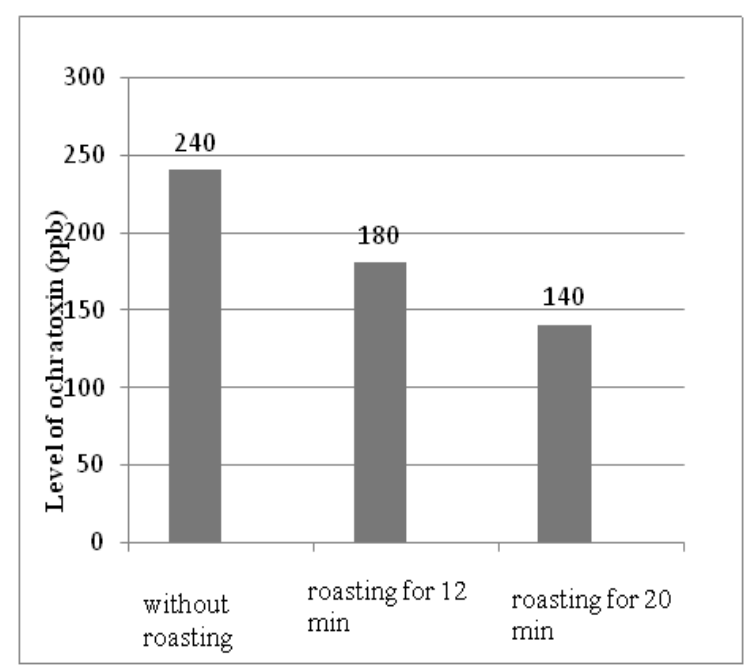

Fig. 6. Effect of roast on ochratoxin A

The temperature had a marked influence on amount of ochratoxin $\mathrm{A}$, where the roasting time was varied and roast colored varied from light medium to dark. After roasting the level of ochratoxin was decreased by $50 \%$. Before roasting the coffee sample contained $240 \mathrm{ppb}$ of ochratoxin A. The level of ochratoxin A after roasting up to 12 minute at $120^{\circ} \mathrm{C}$ was reduced to $180 \mathrm{ppb}$. Roasting time increased up to 20 minute reduced level of the ochratoxin to $120 \mathrm{ppb}$.

Among 65 samples of coffee, 53 samples were contaminated with different types of fungi like Aspergillus spp. Mucor spp. Rhizopus spp. etc. Among them A. ochraceus was isolated from two samples only, where the A.ochraceus was confirmed by using CYA media as they showed yellow brown color on CYA.The low contamination of A. ochraceus on this study may be probably due to good drying and storage condition as well as proper processing. Similar observations were found by several authors (Frank 2001, Bucheli et al. 2000), who failed to isolate ochratoxigenic moulds from fresh cherries. This was attributed to the presence of species adapted to high moisture (yeast, bacteria or other moulds) that may inhibit their growth. However, a high level of contamination by yeast and moulds including $A$. ochraceus and A. niger was observed in raw coffee beans collected from different regions of Brazil (Urbano et al. 2001). Lin et al. (2005) analysed 51 samples of coffee among which $13(25 \%)$ coffee samples contained 0.1 0.5ppb level of ochratoxin.
The growth curve (Fig. 1) of fungal isolates $\mathrm{AO}_{1}$ and $\mathrm{AO}_{2}$ shows linear growth pattern. The maximum size of fungal isolates $\mathrm{AO}_{1}$ and $\mathrm{AO}_{2}$ were obtained on $13^{\text {th }}$ day which were $85 \mathrm{~mm}$ and $86 \mathrm{~mm}$ respectively. $\mathrm{AO}_{2}$ had larger colony size than $\mathrm{AO}_{1}$.

The optimum condition the growth of A. ochraceus and production of ochratoxin was $60 \%$ moisture content, where the isolated strain was inoculated in coffee sample at different moisture content. High yield of ochratoxin was obtained after 19 days of incubation in $60 \%$ moisture content. According to Northolt et al. (1979) A. ochraceus had the ability to grow at water activity $\left(\mathrm{a}_{\mathrm{w}}\right)$ as low as 0.79 and reported optimum $\mathrm{a}_{\mathrm{w}}$ for growth was 0.95 . The minimum $\mathrm{a}_{\mathrm{w}}$ for toxin production by $A$. ochraceus varied from 0.83 to 0.87 with an optimum of 0.99 .

The level of ochratoxin was decreased by $50 \%$ after roasting the coffee beans till they turned out to dark color. According to Mounjouenpou et al. (2012) this reduction may be due to the formation of brown compounds such as melanoidins due to Maillard reactions. These, highly reactive compounds should be responsible for ochratoxin A complication observed. The intensity of the formation of these brown products is a function of the degree of roasting: This explains the low rate of complication observed with light roasted coffee. Suarez-Quiroz et al. (2005) suggested that OTA was masked by reactions with the substrate during roasting. The absence of OTA in green coffee beans is therefore the best guarantee of safety.

\section{Acknowledgements}

We thank the staff of the Department of Microbiology, National College, Khusibu, Kathmandu for their kind co-operation throughout the work.

\section{Reference}

Aneja, K.R. 2008. Experiments in microbiology, plant pathology and biotechnology. $4^{\text {th }} \mathrm{ed}^{\mathrm{n}}$. New Age International (P) limited publishers, Ansari Road, Daryaganj, NewDelhi.

Bacon, C.W., J.G. Sweeney, J.D. Robbins and D. Burdick. 1973. Production of penicillic acid and ochratoxin A on poultry feed by Aspergillus ochraceus: temperature and moisture requirements. Appl. Microbiol. 26(2): 155-160.

Bucheli, P., C. Kanchanomai, I. Meyer and A. Pittet. 2000. Development of ochratoxin A during Robusta (Cô̂ea canefora) coûee cherry drying. J. Agric. Food Chem. 48: $1358-1362$. 
Frank, J.M. 2001. On the activity of fungi in coûee in relation to ochratoxin A production. In: 19th ASIC Coffee Conference 14-18 May Trieste, Italy.

Helrich, K. 1990. Official methods of analysis of the association of official analytical chemists AOAC, Inc. $15^{\text {th }} \mathrm{ed}^{\text {n }}$, Washington, DC, chapter 49, Pp.12071209.

Hohler, D. 1998. Ochratoxin A in food and feed: occurrence, legislation and mode of action. $Z$ Ernahrungswiss 37 (1) : 2-12.

IARC. 1993. Ochratoxin A. Monographs on the Evaluation of Carcinogenic Risk to Humans. Lyon, France, IARC Working Group, World Health Organization. Pp. 250-277.

IGAFN. 1980. International groundnut Aspergillus flavus. Nursury ICRISAT.J, 1-25.

KC, J.B and B.K. Rai. 2007. Basic Food Analysis Hand book, $1^{\text {st }}$ edn. Prompt Printers Pvt. Ltd. Nepal.

Khoury, A and A. Atoui. 2010. Ochratoxin A: General Overview and Actual Molecular Status, Toxin (Basel) 2 (4) : 461-493.

Le-Bars, J and P. Le-Bars. 2000. Mycotoxigenesis in Grains Application to Mycotoxic Prevention in Coffee. In: Coffee Biotechnology and Quality. (Eds. T. Sera, C.R. Soccol, A. Pandey and S. Raussos). Kluwer Academic Publisers, Netherlands, pp. 355368.

Lindenfelser, L.A and A. Ciegler, 1975. Solid-Substrate Fermentor for Ochratoxin A Production. Appl. Microbiol. 29 (30): 323-327.

Lin L.C., P.C. Chen., Y.M. Fu and D.Y.C. Shih. 2005. OchratoxinA contamination in coffees, cereals, red wines and beers in Taiwan. J. Food Drug Anal. 13(1): 84-92.

Mello. J.P.F and A.M.C. Macdonald. 1997. Mycotoxins. Animal Feed Sciences Technology 69: 155-166.
Mounjouenpou P., F. Justin.,, B. Guyot and J.P. Guiraud. 2012. Study of Ochratoxin: A complexation in coffee. Asian J. Plant Sci. Res. 2 (5):570-576.

Nepal, A. 2006. Soil nutrient analysis of organic coffee farm in Gulmi district. Journal of Himalayan college of Agricultural science and Tecnology 4(1): 104-105.

Northolt, M.D., H.P. Van Egmond and W.E Paulsch. 1979. Ochratoxin A production by some fungal species in relation to water activity and temperature. Journal of Food Protection 42: 485-490

Pitt, J.I and A.D Hocking. 1997. Fungi and Food Spoilage, 2nd edn, London, Blackie Academic and Professional.

Pitt J.I. 1987. Penicillium viridicatum, Penicillium verrucosum, and production of ochratoxin A. Appl. Environ. Microbiol. 53: 266-269.

Pitt, J.I. 2000. Toxigenic fungi and mycotoxins. Food Science Australia 56(1): 184-92.

Peraica, M., B. Radic., A. Lucic and M. Pavlovic. 1999. Toxic effects of mycotoxins in humans Bulletin of the World Health Organization 77 (9):754-766.

Smith, J.E and M.O. Moss. 1985. Mycotoxins Formation, analysis and significance. John Wiely and Sons, Chichester.

Suarez-Quiroz, M., B. De Louise., O. Gonzales-Rios., M. Borel., B. Guyot., S. Schorr-Galindo and J.P. Guiraud. 2005. The impact of roasting on the ochratoxin A content of coffee. International Journal of Food Science and Technology 40: 605-611.

Urbano, G.R., M.H. Taniwaki., M.F.D.F. Leitao and M.C. Vicentini. 2001. Occurrence of ochratoxin A producing fungi in raw Brazilian coûee. J. Food. Prot. 68: 12261230.

Van Der Stegen, G.H.D., P.J.M. Essens and J. van der Lijn. 2001. Effect of roasting conditions on reduction of ochratoxin A in coffee. J. Agric. Food chem .49(10): 4713-4715. 